\title{
Prostate Cancer, Treatment Modalities and Complications: An Evaluation of the Scientific Literature
}

\author{
Sebastião David Santos-Filho ${ }^{1}$, Sotiris Missailids ${ }^{2}$, Adenilson de Souza da Fonseca ${ }^{1,3}$ and \\ Mario Bernardo-Filho ${ }^{1,4}$ \\ ${ }^{I}$ Departamento de Biofísica e Biometria; Instituto de Biologia Roberto Alcântara Gomes; Universidade do Estado \\ do Rio de Janeiro; Av. 28 de Setembro, 87; 20551030; santos-filho@uer.br; Rio de Janeiro - RJ - Brasil. \\ ${ }^{2}$ Department of Chemistry and Analytical Sciences; The Open University, Walton Hall; Milton Keynes; MK7 6AA, \\ UK. ${ }^{3}$ Centro de Ciências da Saúde; Centro Universitário Serra dos Órgãos; Av. Alberto Torres, 111; 25964004; \\ Teresópolis - RJ - Brasil. ${ }^{4}$ Coordenadoria de Pesquisa; Instituto Nacional do Câncer; 20230130; Rio de Janeiro - \\ RJ - Brasil
}

\begin{abstract}
Prostate (PR) cancer $(C A)$ is one of the most common malignant neoplasms in men all over the world. In general, if prostate cancer $(P C)$ is detected early, treatment usually involves either surgical removal of the prostate or radiotherapy $(R T)$. Hormone Therapy $(H T)$ or chemotherapy $(C H)$ is the preferred treatment for more advanced cases of PC or if CA spreads beyond the PT. A number of complications, such as urinary incontinence (IU) or erectile dysfunction (ED), can be associated with some modalities of treatment of the PC. The aim of this work is to evaluate, in PubMed, the number of publications related with prostate cancer and the main modalities of treatment, as well as some clinical complications. The searches were performed in PubMed (http://www.ncbi.nlm.nih.gov/entrez/query.fcgi) in the period 1950 to 2008 using the words: (i) CA, (ii) CA and PR or penis or testis, (iii) $C A$ and $P R$ and $R T, C A$ and $P R$ and surgery (SU), $C A$ and $P R$ and $C H$ and, $C A$ and $P R$ and $H T$ and (iv) $C A$ and $P R$ and $R T$ and IU or ED, CA and PR and SU and IU or ED, CA and PR and CH and IU or ED and, $C A$ and $P R$ and $H T$ and $C H$ and $I U$ or ED, and (V) PC and the same modalities of treatment. The data was obtained on July 20th, 2008. PC, as expected has been cited extensively and surgery has been identified as the most widely referenced modality of treatment. Furthermore, urinary incontinence and erectile dysfunction are important complications that have attracted significant scientific interest. In conclusion, these findings have shown the relevance of the PubMed to analyze quantitatively the publications in cancer and this information could be worthwhile in aiding the comprehension of some clinical aspects related with PC, as well as the development of preventative actions. The analysis of the scientific interest, considering the number of publications in the PubMed, reveals research trends in the field and demonstrates the importance of the surgical procedures in the treatment of the prostate cancer. Moreover, this finding is relevant due to the fact that surgery is the treatment of choice when early detection of $P C$ is achieved. However, it is important to consider clinical complications related to such procedures, such as urinary incontinence and erectile dysfunctions that can reduce the quality of life of the patient.
\end{abstract}

Key words: Prostate cancer, radiotherapy, PubMed, scientific interest

\section{INTRODUCTION}

Prostate (PR) cancer (CA) is one of the most common malignant neoplasm in men all over the world (Antilla et al., 2005), as well as in Brazil (http://www.inca.gov.br/estimativa/2008/finalversi on.pdf) in particular and is the third most common cancer worldwide and the most common cancer in

\footnotetext{
${ }^{*}$ Author for correspondence
} 
the North American continent (Boulikas, 2008; http://info.cancerresearchuk.org/cancerstats/geogra phic/world/commoncancers/). Despite prostate cancer's high incidence, relatively little is known of its etiology. Long asymptomatic period and slow growth rate of the tumor have hampered studies on the etiologic hypotheses (Antilla et al., 2005). Prostate cancer incidence rates are still increasing steadily (Neutel et al., 2007) and worldwide disparities exist between geographic regions with regards to prostate cancer (PC) incidence and mortality. Countries in East Asia have lower rates of PC compared to Western countries such as Canada and the United States (Goetzl et al., 2007), although the incidence of PC has been increasing in recent years in China (Song et al., 2007). The large difference between the incidence of PC and the mortality associated with this disease suggests that a large number of men do not require treatment (Albertsen, 2006).

Prostate cancer is rare below age 40, with incidence rates doubling each subsequent decade of life after that. Family history and ethnicity/ country of residence are the only firmly established risk factors for PC (Antilla et al., 2005). Schimid et al., 2007 reported that other risk factors for PC include increasing age, ethnic origin, and familial/hereditary factors. Yet, the epidemiology of PC gives some indications that its etiology is probably not only genetic, but also environmental.

Prostate cancer is an ideal candidate for exogenous preventive measures, such as dietary and pharmacological prevention, due to some specific features associated with the disease: high prevalence, long latency, endocrine dependency, availability of serum markers and histological precursor lesions (Schimid HP et al., 2007). Some authors (Schimid et al., 2007; Goetzl et al., 2007) have reported that dietary/nutritional factors that may influence disease development include total energy intake, dietary fat, cooked meat, micronutrients and vitamins, fruit and vegetable intake, minerals and phytoestrogens.

Prostate cancer preferentially metastasizes to regional lymph nodes and bone. The incidence of metastasis has been reduced over the last years, mainly due to early detection based on the determination of prostate-specific-antigen (PSA) (Garin, 2006), as well as the digital rectal examination, transrectal ulstrasonography (TRUS) and TRUS-guided biopsies (Futterer et al., 2008).
Imaging techniques help the diagnosis of diseases in general (Lomeña and Soler, 2005) and play a central role in the detection, localization, staging, and local recurrence detection in patients who suffer from PC (Futterer et al., 2008). The modalities for the treatment of PC depend on the stage of the disease, the age of the individual and the presence of other clinical conditions. In general, if PC is detected early, treatment usually involves either surgical removal of the prostate or radiotherapy (RT). For more advanced cases of $\mathrm{PC}$, or, if cancer spreads beyond the prostate, hormone therapy (HT) or chemotherapy (CT) are the treatments of choice. (Pendleton et al., 2007).

Relevant complications, as urinary incontinence or erectile dysfunction, can be associated with some treatment modalities of PC (Escudero et al., 2006; Zagar et al., 2007). Chatoor et al. (2007) reported that radical prostatectomy and radiotherapy of PC could also cause of fecal incontinence.

PubMed is a service of the U.S. National Library of Medicine that includes over 16 million MEDLINE citations and other life science journals for biomedical articles back to the 1950s. PubMed, which is used as a tool in various publications, includes links to full text articles and other related resources. Garg et al (2006) have used medical literature databases including PubMed to compile and review data on radiation proctopathy in the treatment of prostate cancer with respect to epidemiology, clinical manifestations, risk factors, pathogenesis, and treatment. Nishino et al., 2006, have evaluated the association between tobacco smoking and gastric cancer risk among the Japanese population, based on a systematic review of epidemiologic evidence and original data were collected by searches of MEDLINE using PubMed, complemented by manual searches.

As the increasing interest of the scientific community in oncology is evident worldwide, the aim of this work is to evaluate, in the PubMed, the number of publications related to $\mathrm{PC}$, the main modalities of treatment and possible complications associated with the treatments, as well as look at trends in the research and therapeutic directions related with this disease. This information could be useful in developing actions for the prevention of prostate cancer, as well as in understanding and discussing the therapeutic modalities available for PC and informing patients about the possible clinical disorders associated with these treatments. 


\section{MATERIAL AND METHODS}

The searches were performed in PubMed (http://www.ncbi.nlm.nih.gov/entrez/query.fcgi) for the period 1950 to 2008 using the words: (i) cancer (CA), (ii) CA and PR, (iii) CA and testis and (iv) $\mathrm{CA}$ and penis.

A search using the words CA and PR were associated with the modalities of treatment, RT or surgery (SG) or CT or HT. Moreover, another search using the words "prostate cancer" (PC), also associated with the modalities of treatment, was performed to evaluate consistency.

Statistical analysis involved Chi-Squared Test, with a significance level of $P<0.05$, was performed comparing the searches using " $\mathrm{CA}$ and $\mathrm{PR}$ and modalities of treatment" and "PC and modalities of treatment". InStat Graphpad software was used to perform statistical analysis (GraphPad InStat version 3.01 for Windows 95/NT, GraphPad Software, San Diego Ca, USA).

Another search was performed using (a) CA and PR and RT and urinary incontinence (UI) or erectile dysfunction (ED), (b) CA and PR and SG and UI or ED, (c) CA and PR and CT and UI or ED or anal incontinence (AI) and (d) CA and PR and HT and CT and UI or ED or AI.
Finally, a search using the above parameters was performed for the same date of the years 1968, 1978, 1988, 1998 and 2008 to decipher any trends associated with preferred choices of treatment as new modalities become available. The data were obtained on July $20^{\text {th }}, 2008$ and the number of citations for each subject was determined.

\section{RESULTS}

Table 1 shows the number of publications found in the PubMed on CA as well as CA and various organs of the male reproductive tract. The results show a high number of publications in cancer, of which nearly $3 \%$ are associated with PR.

Table 2 shows the number of publications cited in the PubMed on CA and PT and the main modalities of treatment, as well as PC and the same modalities of treatment. Surgery has been shown to be the modality of treatment associated with prostate cancer that is most widely cited when compared with RT, CT and HT, whilst RT and HT are the least cited ones. The comparison between CA and PT and PC was very significant $(P<0.01)$ in all modalities of treatment.

Table 1- Number of publications cited in PubMed on CA, as well as, CA and various organs of the male reproductive tract.

\begin{tabular}{cc}
\hline Selected subject & Number of publications \\
\hline CA & 2174533 \\
CA and PR & 63560 \\
CA and testis & 12212 \\
CA and penis & 4745 \\
\hline
\end{tabular}

Table 2 - Comparison of the number of publications cited in PubMed on CA and PT and the main modalities of treatment, as well as PC and the same modalities of treatment.

\begin{tabular}{ccc}
\hline Subject & CA and PT & PC \\
\hline RT & 8585 & 5467 \\
SG & 18531 & 11226 \\
CT & 11867 & 8234 \\
HT & 8202 & 5936 \\
\hline
\end{tabular}

Table 3 shows the number of publications cited in the PubMed on some complications associated with modalities of treatment for PC. Urinary incontinence and erectile dysfunction have been mainly associated with surgery.

The number of publications involving prostate cancer and the studied modalities of treatment with anal (fecal) incontinence is very poor.
Table 4 shows the number of publications found in PubMed on CA and PR and the main therapeutic modalities in order to demonstrate changes in the trends of research and publications on PC treatments within the last 50 years. 
Table 3 - Number of publications cited in PubMed on some complications associated with modalities of treatment for prostate cancer.

\begin{tabular}{cc} 
Subject & Number of publications \\
\hline CA and PR and RT and UI & 233 \\
CA and PR and RT and ED & 299 \\
CA and PR and SG and UI & 558 \\
CA and PR and SG and ED & 523 \\
CA and PR and CT and UI & 43 \\
CA and PR and CT and ED & 159 \\
CA and PR and HT and UI & 28 \\
CA and PR and HT and ED & 106 \\
\hline
\end{tabular}

Table 4 - Number of publications cited in PubMed on CA and PR and the main modalities of treatment over the past 50 years.

\begin{tabular}{ccccc}
\hline Year & $\begin{array}{c}\text { CA and PR and } \\
\text { RT }\end{array}$ & $\begin{array}{c}\text { CA and PR and } \\
\text { CH }\end{array}$ & $\begin{array}{c}\text { CA and PR and } \\
\text { SG }\end{array}$ & $\begin{array}{c}\text { CA and PR and } \\
\text { HT }\end{array}$ \\
\hline 1968 & 57 & 60 & 359 & 254 \\
1978 & 235 & 419 & 1016 & 573 \\
1988 & 797 & 1427 & 2540 & 1446 \\
1998 & 2623 & 3826 & 7388 & 3328 \\
2008 & 8585 & 11867 & 18531 & 8202 \\
\hline
\end{tabular}

\section{DISCUSSION}

Although mortality from prostate cancer has been declining over the past decade, metastasis, which is presented in approximately $20 \%$ of patients, can substantially shorten survival time and remains a major challenge in maintaining quality of life for survivors (Choueiri et al., 2006; Kabeer et al., 2007). As reported by Schimid et al. 2007, prostate cancer is basically an ideal candidate for exogenous preventive measures, such as dietary and pharmacological prevention. Moreover, Schimid et al. (2007) and Goetzl et al. (2007) have also reported that dietary/nutritional factors may influence the disease development. These scientific considerations are worthwhile in order to develop a prevention strategy against prostate cancer. Our study revealed that a high percentage of publications (about 3\%) on cancer, cited in the PubMed, are related with prostate (see Table 1).

The analysis of the number of publications found in the PubMed related with the possible types of treatment of prostate cancer has shown that surgery is more studied than the other treatment modalities of this disease. This could be related to the fact that the treatment modality of choice for prostate cancer depend on the stage of the disease, the age of the individual and the presence of other clinical conditions. As a consequence, in general, if prostate cancer is detected early, treatment usually involves radical retropubic prostatectomy (Escudero et al., 2006; Kibel et al., 2007). The improvement of the assays for early detection of prostate cancer has thus favored the use of surgery, as a curative modality to treat prostate cancer. Thus, although other modalities, such as brachytherapy, have come to focus lately with particular applications on prostate cancer, surgery has been and remains the more cited therapeutic approach for prostate cancer (see Tables 2 and 4). Yet, more scientific studies about the use of radiotherapy in the treatment of the prostate could come into focus due to the variety of possible sources of radiation (Marshall, 2007; Fang et al., 2008; Ganswindt et al., 2008) and the potential they offer to reduce the number/intensity of complications associated with surgery. With regards to such trends, it is interesting to note that, although hormone therapy had 5 times more publications than radiotherapy in Jul 1968, it had twice as many in 1978 and 1988 and has the same or slightly less publications in Jul 2008, showing a smaller rate of increase in this field. On the other hand, chemotherapy had the same number of publications with radiotherapy in 1968 but nearly twice as many in 1978 and 1988, a period of peak 
for medicinal chemistry, with the gap slowly decreasing in more recent years.

Escudero et al. (2006) and Zagar et al. (2007) have reported that such complications as urinary incontinence or erectile dysfunction can be associated with some treatment modalities of prostate cancer. The anal (fecal) incontinence is also cited as a complication of the treatment of prostate cancer, although its reference in current literature is minimal. Furthermore, the undesirable complications of urinary incontinence and erectile dysfunction have been associated mainly with surgery and radiotherapy treatments. The ratio (erectile dysfunction/urinary incontinence) between these two modalities of treatment was 1.30 to radiotherapy and 0.93 to surgery. However, the ratios are very different if one considers chemotherapy (3.69) and hormone therapy (3.91). In conclusion, these findings have shown the relevance of PubMed in the quantitative analysis of publications in cancer, although caution should be recommended on the way the searches are preformed due to discrepancies in data obtained by using different expressions of the same search terms. This information could be valuable for the comprehension of clinical aspects related to prostate cancer, as well as the development of preventative actions. The analysis of the scientific interest, considering publications in the PubMed, shows the importance of surgical procedures in the treatment of prostate cancer. This finding is relevant due to the fact that surgery is also the indicated treatment for prostate cancer at the early stages (following early detection). However, it is important to consider clinical complications, such as urinary incontinence and erectile dysfunctions, which can reduce the quality of life of the patient.

\section{ACKNOWLEDGMENTS}

We thank CNPq, FAPERJ, UERJ and The Open University for their support.

\section{RESUMO}

O câncer (CA) de próstata (PT) é um dos neoplasmas malignos mais comuns no homem no mundo todo. Em geral, se o câncer de próstata (PC) é detectado tardiamente, o tratamento usualmente envolve ou a remoção cirúrgica da próstata ou radioterapia (RT). Tratamento por hormônio (HT) ou quimioterapia $(\mathrm{CH})$ é o preferido para muitos casos avançados de $\mathrm{PC}$ ou se o CA se distribuir além da PT. As complicações como incontinência urinária (IU) ou disfunção erétil (ED), podem ser associadas com algumas modalidades de tratamento do câncer de próstata. O objetivo desse trabalho foi avaliar, no PubMed, o número de publicações relacionado com câncer de próstata e algumas modalidades de tratamento, como também algumas complicações clínicas. A pesquisa foi realizada no PubMed (http://www.ncbi.nlm.nih.gov/entrez/query.fcgi) no período de 1950 à 2008 usando as palavras: (i) CA, (ii) CA e PR ou penis ou testis, (iii) CA e PR e RT, CA e PR e surgery (SU), CA e PR e CH e, CA e PR e HT, (iv) CA e PR e RT e IU ou ED, CA e PR e SU e IU ou ED, CA e PR e CH e IU ou ED e, CA e PR e HT e CH e IU ou ED, e (V) PC e as mesmas modalidades de tratamento. $\mathrm{O}$ resultado foi obtido em 20/07/ 2008. O câncer de próstata tem sido muito citado tanto quanto a cirurgia é a modalidade de tratamento e incontinência urinária e disfunção erétil são importantes complicações. Concluindo, esses achados tem mostrado a relevância do PubMed para analisar quantitativamente as publicações em câncer e essas informações poderiam ser de valor e ajudar na compreensão de alguns aspectos clínicos relacionados com o câncer de próstata, assim como o desenvolvimento de ações preventivas. A análise do interesse científico, considerando as publicações no PubMed, mostram a importância dos procedimentos cirúrgicos no tratamento do câncer de próstata. Além disso, esse resultado é relevante devido à cirurgia ser também o tratamento usado quando é feita uma detecção tardia do câncer de próstata. Embora, seja importante considerar as complicações clínicas, como a incontinência urinária e a disfunção erétil que podem reduzir a qualidade de vida do homem. Palavras-chaves: câncer de próstata, radioterapia, PubMed, interesse científico.

\section{REFERENCES}

Albertsen, P. C. (2006), PSA and the conservative treatment of early prostate cancer. Arch Ital Urol Androl., 78, 152-153.

Anttila, T.; Tenkanen, L.; Lumme, S. et al. (2005), Chlamydial Antibodies and Risk of Prostate Cancer. Cancer Epidemiol Biomarkers Prev., 14. 385-389. 
Boulicas, T. (2008), Introduction to Anticancer Therapeutics. In-Anticancer Therapeutics, Missailidis S (editor). Wiley and Sons Ltd, UK.

Chatoor, D. R.; Taylor, S. J.; Cohen, C. R. G.; Emmanuel, A. V. (2007), Faecal incontinence. $B r J$ Surg., 94, 134-144.

Choueiri, M. B.; Tu, S. M.; Yu-Lee, L. Y.; Lin, S. H. (2006), The central role of osteoblasts in the metastasis of prostate cancer. Cancer Metastasis Rev., 25, 601-609.

Escudero, J. U.; Ramos, M. C.; Ordono, F. D.; Fabuel, M. D.; Navalon, P. V.; Zaragoza, J. O. (2006), Radical prostatectomy complications: evolution and conservative management of urinary incontinence. Actas Urol Esp., 30, 991-997.

Fang, F. M.; Wang, Y. M.; Huang, H. Y.; Chiang, P. H. (2008), Comparison of the Outcome and Morbidity for Localized or Locally Advanced Prostate Cancer Treated by High dose-date Brachytherapy Plus External Beam Radiotherapy (EBRT) Versus EBRT Alone. Jpn J Clin Oncol., 38, 474-479.

Futterer, J. J.; Heijmink, S.; Spermon, J. (2008), Imaging the male reproductive tract: current trends and future directions. Radiol Clin North Am., 46, 133147.

Ganswindt, U.; Stenzl, A.; Belka, C. (2008), adjuvant radiotherapy for patients with locally advanced prostate cancer -new standard? Eur Urol., 5, 528-542.

Garg, A. K.; Mai, W. Y.; McGary, J. E.; Grant, W. H. 3rd; Butler, E. B.; Teh, B. S. (2006), Radiation proctopathy in the treatment of prostate cancer. Int $J$ Radiat Oncol Biol Phys., 66, 1294-1305.

Garin, J. A.; Mas, A. G. (2006), The diagnosis of prostate cancer dissemination. Arch Esp Urol., 59, 1011-1020.

Goetzl, M. A.; Vanveldhuizen, P. J.; Thrasher, J. B. (2007), The effects of soy phytoestrogens on the prostate. Prostate Cancer Prostatic Dis., 10, 216-223. http://info.cancerresearchuk.org/cancerstats/geographic/ world/commoncancers/ (assessed Aug. 2008).
Kabeer, M. A.; Lloyd-Davies, E.; Maskell, G.; Hohle, R.; Mathew, J. (2007), Metastatic prostate cancer masquerading clinically and radiologically as a primary caecal carcinoma. World J Surg Oncol., 5, 2.

Kibel, A. S.; Nelson, J. B. (2007), Adjuvant and salvage treatment options for patients with high risk prostate cancer treated with radical prostatectomy. Prostate Cancer Prostatic Dis., 10, 119-126.

Lomeña, F.; Soler, M. (2005), Clinical application of PET. Braz Arch Biol Technol., 48, 179-183.

Marshall, D. T. (2007), Options and recent advances in permanent brachytherapy for prostate cancer. Can $J$ Urol., 14, 28-31.

Neutel, C. I.; Gao, R. N.; Blood, P. A.; Gaudette, L. A. (2007), The changing age distribution of prostate cancer in Canada. Can J Public Health., 98, 60-64.

Nishino, Y.; Inoue, M.; Tsuji, I.; Wakai, K.; Nagata, C.; Mizoue, T.; Tanaka, K.; Tsugane, S. (2006), Tobacco smoking and gastric cancer risk: an evaluation based on a systematic review of epidemiologic evidence among the Japanese population. Jpn J Clin Oncol., 36, 800-807.

Pendleton, J.; Pisters, L. L.; Nakamura, K.; Anai, S.; Rosser, C. J. (2007), Neoadjuvant therapy before radical prostatectomy: where have we been? Where are we going? Urol Oncol., 25, 11-18.

Schimid, H. P.; Engeler, D. S.; Pummer, K.; SchmitzDrager, B. J. (2007), Prevention of prostate cancer: more questions than data. Recent Results Cancer Res., 174, 101-107.

Song, H. Z.; Chen, L. B. (2007), Advances in researches on hormonal refractory prostate cancer. Zhonghua Nan Ke Xue, 13, 57-60.

Zagar, T. M.; Stock, R. G.; Casaretti, J. A.; Stone, N. N. (2007), Assessment of postbrachytherapy sexual function: a comparison of the IIEF-5 and the MSEFS. Brachytherapy, 6, 26-3.
Received: August 25, 2008; Revised: September 09, 2008; Accepted: September 11, 2008. 